\title{
Tumor Laterality Left
}

National Cancer Institute

\section{Source}

National Cancer Institute. Tumor Laterality Left. NCI Thesaurus. Code C160200.

A finding indicating the tumor location is on the left side of the specimen. 